\title{
Effects of Treatment on the Mortality Rate in Septicaemia
}

\author{
J. P. CHALMERS, ${ }^{*}$ PH.D., M.R.A.C.P. ; D. J. TILLER, $†$ M.R.A.C.P.
}

$S^{m}$ ummary : The results of treatment have been analysed in 173 patients with septicaemia during 1962-8. Between 1962 and 1965 various antibiotics were used, and shock was treated with vasopressor agents. Between 1966 and 1968 kanamycin was given initially, and shock was treated with corticosteroids and with intravenous fluid therapy monitored with a central venous pressure manometer.

The mortality rate in $1966-8$ fell to half that of the earlier period in patients with Gram-negative infections, and in those with shock. The reduced mortality in the latter was clearly associated with the use of a central venous manometer to control intravenous fluid therapy, though whether the reduction resulted from specific improvement in intravenous therapy or from the necessary closer observation of the patient is not clear. Staphylococcal septicaemia was common during both periods, and its mortality rate did not fall; hence methicillin together with kanamycin is now given initially in all cases.

\section{Introduction}

The treatment of septicaemia, especially when complicated by shock, has undergone marked changes in the last decade, but despite the introduction of many new therapeutic measures the mortality remains high (Melby and Spink, 1958 ; Gourzis et al., 1961 ; Blair et al., 1961 ; McCabe and Jackson, 1962 ; Bennett et al., 1963 ; Lillihei et al., 1964 ; Weil et al., 1964 ; Hodgin and Sanford, 1965 ; Maclean et al., 1965 ; du Toit et al., 1966 ; Kardos, 1966 ; Anderson et al., 1967 ; Siegel et al., 1967).

In the present study a comparison of the mortality rates of patients with septicaemia in 1962-5 and in 1966-8 in a large general hospital shows a significant improvement in the survival of patients with Gram-negative infections and of those with shock, coinciding with a number of changes in the approach to treatment. The contribution of these changes to the reduction in mortality is analysed below.

\section{Materials and Methods}

This report is based on 173 patients in whom a clinical diagnosis of septicaemia was confirmed by a positive blood culture in the period 1 January 1962 to 30 April 1968. The clinical and laboratory data obtained from case records were correlated with mortality to assess the efficacy of the therapeutic measures used. Shoek was arbitrarily defined as a reduction in systolic blood pressure to less than $90 \mathrm{~mm}$. $\mathrm{Hg}$ or by more than $50 \mathrm{~mm} . \mathrm{Hg}$ in a known hypertensive patient. These criteria for the diagnosis of shock were applied without change in 1962-5 and 1966-8.

\section{Treatment 1962-5}

Antibiotics used in this period included tetracycline, chloramphenicol, erythromycin, streptomycin, and penicillin in various combinations. When shock occurred either noradrenaline or metaraminol was given in an attempt to maintain the arterial blood pressure.

\section{Treatment 1966-8}

Kanamycin.-One gramme of kanamycin was given intravenously as soon as a provisional diagnosis of septicaemia was made, and subsequent dosage was adjusted so as to maintain blood kanamycin levels below $30 \mu \mathrm{g} . / \mathrm{ml}$., since toxic effects are rare below this level. A dose of $250 \mathrm{mg}$. every eight hours was safe in patients with normal renal function and was continued for one week unless the results of the blood culture and sensitivity tests made it necessary to use other antibiotics.

Shock.-Whenever a patient was shocked $1 \mathrm{~g}$. of hydrocortisone (Intracort) or its equivalent, $40 \mathrm{mg}$. of dexamethasone (Decadron), was given intravenously. Since the patients were under the care of many different physicians and surgeons, some were given no corticosteroids at all, whereas others received inadequate doses. No patient is shown as receiving corticosteroids unless more than $500 \mathrm{mg}$. was given in the initial intravenous dose, since many authors have shown that smaller doses do not affect the outcome (Melby and Spink, 1958; Spink and Vick, 1961; McCabe and Jackson, 1962; Weil, 1962 ; Weil et al., 1964 ; Hodgin and Sanford, 1965). The central venous pressure was monitored in patients with shock by means of a polyethylene catheter inserted through the antecubital vein, advanced into the chest, and then connected to a saline manometer (Smith and Moore, 1962 ; McGowan and Walters, 1963 ; Prout, 1968). Frequent measurements of the central venous pressure were used to control fluid therapy so as to maintain the central venous pressure between 10 and 15 $\mathrm{cm}$. of water relative to the mid-axillary line with the patient supine. Digitalis was given to patients in heart failure, and to those in whom fluid therapy raised the central venous pressure without restoration of systemic arterial blood pressure. In cases where hypotension and a raised central venous pressure persisted a beta-adrenergic stimulator such as isoprenaline was given.

\section{Clinical Data}

\section{Results}

The clinical features of septicaemia observed in this series were typical of those reported by other authors and will not be dwelt on here (Hassall and Rountree, 1959 ; McCabe and Jackson, 1962 ; McHenry et al., 1962 ; Waisbren, 1964 ; Weil et al., 1964 ; Hodgin and Sanford, 1965). There were 61 patients with septicaemia in $1962-5$ and 112 in 1966-8. These two groups of patients were similar with respect to age, sex, underlying conditions, contributory factors, and results of laboratory tests (Table I). The investigations done in all patients included a haemoglobin, full blood count, blood urea, serum electrolytes, chest $x$-ray examination, and electrocardiogram. The results of these were quite unremarkable and they are not shown in full.

\section{Mortality}

The mortality rate in $1962-5$ was $43 \%$ and in $1966-8$ it was only $28 \%$ (Table II). The improvement in survival was limited to two groups of patients, those with Gram-negative infections and those with shock. 
TABLE I.-Comparison of Patients in 1962-5 and 1966-8 with Respect to Age, Sex, Underlying Conditions, Contributory Factors, and Laboratory Tests

\begin{tabular}{|c|c|c|c|}
\hline & $1962-5$ & $1966-8$ & Total \\
\hline 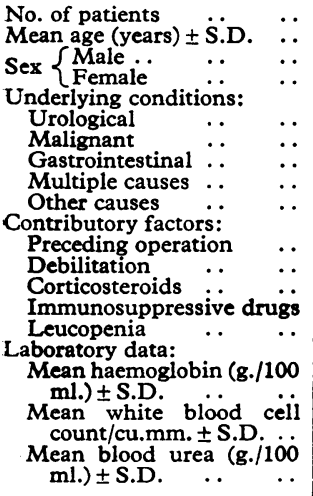 & $\begin{array}{l}61 \\
51 \pm 18 \\
37 \\
24 \\
20 \\
10 \\
9 \\
8 \\
14 \\
18 \\
7 \\
5 \\
0 \\
1\end{array}$ & $\begin{aligned} 112 \\
55 \pm 16 \\
65 \\
47 \\
33 \\
21 \\
22 \\
14 \\
22 \\
30 \\
20 \\
4 \\
2 \\
2 \\
11 \cdot 5 \pm 2 \cdot 0 \\
16,000 \pm 11,000 \\
60 \cdot 5 \pm 50\end{aligned}$ & $\begin{array}{c}173 \\
54 \pm 20 \\
102 \\
71 \\
53 \\
31 \\
31 \\
22 \\
36 \\
48 \\
27 \\
9 \\
2 \\
3 \\
11 \cdot 6 \pm 2 \cdot 1 \\
17,000 \pm 14,000 \\
62 \pm 60\end{array}$ \\
\hline
\end{tabular}

S.D. = Standard deviation

TABLE II.-Mortality, With and Without Shock, for Gram-negative Septicaemia, Staphylococcal Septicaemia, and All Cases Combined

\begin{tabular}{|c|c|c|c|c|c|c|c|c|c|c|}
\hline & & \multicolumn{3}{|c|}{ Gram-negative } & \multicolumn{3}{|c|}{ Staph. aureus* } & \multicolumn{3}{|c|}{ All Cases } \\
\hline & & \multirow{2}{*}{ Total } & \multicolumn{2}{|c|}{ Dead } & \multirow{2}{*}{ Total } & \multicolumn{2}{|c|}{ Dead } & \multirow{2}{*}{ Total } & \multicolumn{2}{|c|}{ Dead } \\
\hline & & & No. & $\%$ & & No. & $\%$ & & No. & $\%$ \\
\hline $\begin{array}{l}\text { All cases }\left\{\begin{array}{l}1962-5 \ldots \\
1966-8 \ldots\end{array}\right. \\
\text { Shock }\left\{\begin{array}{l}1962-5 \\
1966-8\end{array}\right. \\
\text { No shock }\left\{\begin{array}{l}1962-5 \\
1966-8\end{array}\right.\end{array}$ & $\begin{array}{l}\cdots \\
\cdots \\
\cdots \\
\cdots\end{array}$ & $\begin{array}{l}34 \\
75 \\
18 \\
45 \\
16 \\
30\end{array}$ & $\begin{array}{r}18 \\
18 \\
10 \\
13 \\
6 \\
5\end{array}$ & $\begin{array}{l}53 \\
24 \\
56 \\
29 \\
38 \\
17\end{array}$ & $\begin{array}{r}14 \\
30 \\
3 \\
11 \\
11 \\
19\end{array}$ & $\begin{array}{r}6 \\
12 \\
3 \\
3 \\
3 \\
9\end{array}$ & $\begin{array}{r}43 \\
40 \\
100 \\
27 \\
27 \\
47\end{array}$ & $\begin{array}{r}61 \\
112 \\
24 \\
58 \\
37 \\
54\end{array}$ & $\begin{array}{l}26 \\
32 \\
15 \\
17 \\
11 \\
15\end{array}$ & $\begin{array}{l}43 \\
28 \\
63 \\
29 \\
30 \\
28\end{array}$ \\
\hline
\end{tabular}

- The apparent changes in the mortality rate in staphylococcal septicaemia were not significant either in shocked patients $(P<0 \cdot 2)$ or in those without shock $(P<0 \cdot 3)$.

In 1962-5 there were 34 cases of Gram-negative septicaemia with 18 deaths (53\%), whereas in 1966-8 there were 75 cases with 18 deaths $(24 \%)$, a significant reduction $(\mathrm{P}<0.01)$. There was no change in the mortality of patients with Gram-positive infections, as illustrated by the staphylococcal group (Table II). There was a comparable increase in the number of Gramnegative and Gram-positive infections in 1966-8. When staphylococcal septicaemia was last reviewed in this hospital (Hassall and Rountree, 1959) the mean mortality for the period $1950-7$ was found to be $58 \%$.

The mortality was reduced from 63 to $29 \%$ in the sickest group of patients, those with shock $(\mathrm{P}<0.01)$ (Table II). Shock was as common in 1966-8 (53\%) as in 1962-5 (40\%), so that the improved survival in the last three years was not simply due to increased detection of patients with a good prognosis. In the patients without shock there was little change in the overall mortality. Shock was more common in Gram-negative infections, but one-third of the patients with staphylococcal septicaemia became hypotensive, so that shock should not be equated with " Gram-negative septicaemia."

\section{Bacteriological Data}

The organisms responsible for the blood stream infection and the corresponding mortality figures are shown in Table III. The two commonest organisms, Escherichia coli and Staphylococcus aureus, accounted for $30 \%$ and $25 \%$ of all infections respectively. A comparison of the bacteriological findings in the blood and urine of 53 patients showed that where an organism was grown from the urine it was the same as that recovered from the blood in $83 \%$ of patients.

The in-vitro antibiotic sensitivities of the organisms are shown in Table IV. Kanamycin provided the broadest cover, being effective against all Gram-negative organisms except Pseudomonas aeruginosa and for $92 \%$ of Staph. aureus. It was not effective against the streptococcus or the pneumococcus.
Chloramphenicol also provided wide cover according to in-vitro tests. Tetracycline, which was one of the most commonly used antibiotics for septicaemia in 1962-5, was effective in vitro in less than half the infections. Similarly, ampicillin was effective in less than $50 \%$. There were no staphylococci resistant to methicillin in this series.

TABLE III.-Mortality Correlated with Organisms in 1962-5, in 1966-8, and in the Whole Series

\begin{tabular}{|c|c|c|c|c|c|c|c|c|c|}
\hline \multirow{2}{*}{\multicolumn{4}{|c|}{ Organism }} & \multicolumn{2}{|c|}{$1962-5$} & \multicolumn{2}{|c|}{$1966-8$} & \multicolumn{2}{|c|}{ 1962-8 } \\
\hline & & & & Total & Dead & Total & Dead & Total & Dead \\
\hline \multirow{2}{*}{\multicolumn{2}{|c|}{ 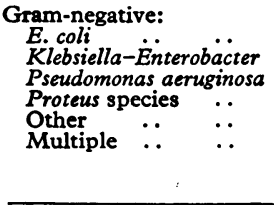 }} & \multirow[t]{2}{*}{$\begin{array}{l}\ddot{ } \\
\ddot{ } \\
\cdots\end{array}$} & \multirow[t]{2}{*}{$\begin{array}{l}\cdots \\
\cdots \\
\cdots \\
\cdots\end{array}$} & $\begin{array}{r}14 \\
11 \\
4 \\
1 \\
0 \\
4\end{array}$ & $\begin{array}{l}6 \\
4 \\
4 \\
0 \\
0 \\
4\end{array}$ & $\begin{array}{r}37 \\
12 \\
10 \\
8 \\
4 \\
4\end{array}$ & $\begin{array}{l}9 \\
3 \\
2 \\
2 \\
1 \\
1\end{array}$ & $\begin{array}{r}51 \\
23 \\
14 \\
9 \\
4 \\
8\end{array}$ & $\begin{array}{r}15 \\
7 \\
6 \\
2 \\
1 \\
5\end{array}$ \\
\hline & & & & 34 & 18 & 75 & 18 & 109 & 36 \\
\hline \multirow{2}{*}{\multicolumn{2}{|c|}{$\begin{array}{l}\text { Gram-positive: } \\
\text { Staph. aureus } \\
\text { Streptococcus species } \\
\text { Str. pneumoniae .. }\end{array}$}} & \multirow[t]{2}{*}{$\ddot{\prime}$} & \multirow[t]{2}{*}{$\because$} & $\begin{array}{r}14 \\
7 \\
6\end{array}$ & $\begin{array}{l}6 \\
1 \\
1\end{array}$ & $\begin{array}{r}30 \\
6 \\
1\end{array}$ & $\begin{array}{r}12 \\
2 \\
0\end{array}$ & $\begin{array}{r}44 \\
13 \\
7\end{array}$ & $\begin{array}{r}18 \\
3 \\
1\end{array}$ \\
\hline & & & & 27 & 8 & 37 & 14 & $64^{\circ}$ & 22 \\
\hline
\end{tabular}

TABLE IV.-In-vitro Antibiotic Sensitivities Correlated with Individual Organisms

\begin{tabular}{|c|c|c|c|c|c|c|c|}
\hline \multirow[b]{2}{*}{ Organism } & \multirow[b]{2}{*}{ No.* } & \multicolumn{6}{|c|}{ Percentage Sensitive to: } \\
\hline & & $\begin{array}{c}\text { Kana- } \\
\text { mycint }\end{array}$ & $\begin{array}{l}\text { Chloram- } \\
\text { phenicol }\end{array}$ & $\begin{array}{c}\text { Strepto- } \\
\text { mycin }\end{array}$ & $\begin{array}{l}\text { Tetra- } \\
\text { cycline }\end{array}$ & $\begin{array}{l}\text { Ampi- } \\
\text { cillin }\end{array}$ & \begin{tabular}{|c} 
Methi- \\
cillin
\end{tabular} \\
\hline $\begin{array}{ll}\text { E. coli } & \ldots \\
\text { Klebsiella-Entero- } & \\
\text { bacter } & \ldots \\
\text { Ps. aeruginosa } & \ldots \\
\text { Proteus species } & \ldots \\
\end{array}$ & $\begin{array}{l}56 \\
25 \\
16 \\
13\end{array}$ & $\begin{array}{l}100 \\
\frac{100}{91}\end{array}$ & $\begin{array}{l}81 \\
64 \\
57 \\
93 \\
\end{array}$ & $\begin{array}{l}90 \\
84 \\
82 \\
77\end{array}$ & $\begin{array}{l}52 \\
44 \\
33 \\
10\end{array}$ & $\frac{24}{63}$ & - \\
\hline $\begin{array}{l}\text { Staph. aureus } \\
\text { Streptococcus species } \\
\text { Pneumococcus }\end{array}$ & $\begin{array}{r}46 \\
14 \\
7\end{array}$ & $\underline{92}$ & $\begin{array}{r}78 \\
93 \\
100\end{array}$ & $\begin{array}{l}57 \\
93 \\
71\end{array}$ & $\begin{array}{r}37 \\
64 \\
100\end{array}$ & $\overline{42}$ & $\underline{100}$ \\
\hline
\end{tabular}

* The numbers of organisms shown in Tables III and IV do not tally exactly owing to the presence of eight patients in whom more than one organism was grown from the blood stream ("Multiple," Table III).

+ Kanamycin was not used in 1962-5 and is therefore based on smaller numbers than shown in column 2. In-vitro sensitivity of Ps. aeruginosa to kanamycin was not routinely assessed.

\section{Mortality Correlated With Therapy}

Antibiotics.-The efficacy of the antibiotics used has been assessed by examining the results for Gram-negative infections, for staphylococcal infections, and for the whole series. While antibiotics are essential in the treatment of patients with septicaemia and were used in all cases, there were no significant differences in the mortality rates of patients treated with different antibiotics (Table V).

TABLE V.-Correlation of Mortality with Antibiotics Used in Gramnegative Septicaemia, Staphylococcal Septicaemia, and All Cases. The Results for 1962-5 and 1966-8 Have Been Pooled Since There is No Significant Difference When the Two Periods are Taken Separately

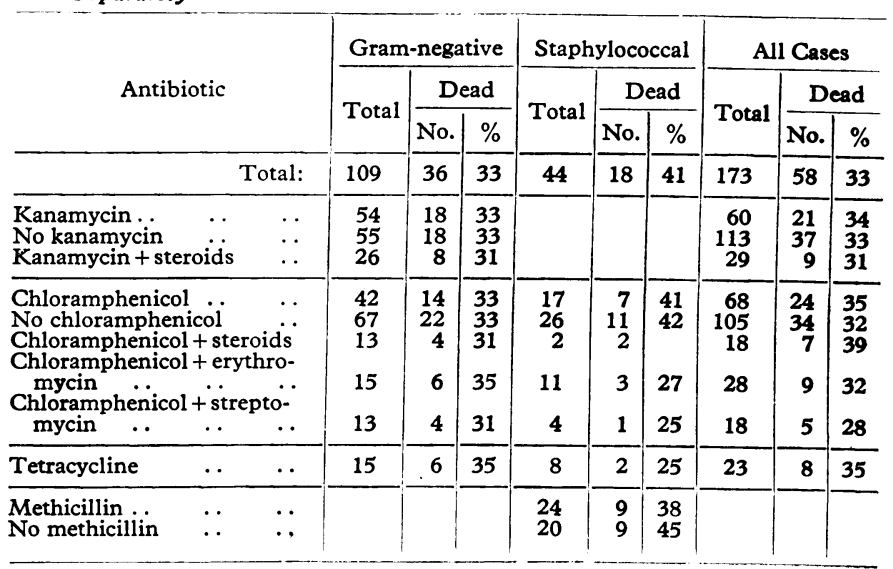




\section{Fluid Therapy and C.V.P. Monitoring}

Twenty-five patients had fluid therapy monitored with a central venous pressure manometer, aiming to keep the central venous pressure between 10 and $15 \mathrm{~cm}$. of water. Only 4 $(16 \%)$ of these 25 patients died (Table VI). Twenty-two patients with shock had their fluid therapy monitored with a central venous pressure manometer and only three of these died $(14 \%)$, whereas $14(40 \%)$ died out of 36 shocked patients who did not have central venous pressure monitoring $(P<0 \cdot 05)$. The fluid used was mainly normal saline, though blood or albumin was occasionally used.

TABLE VI.-Correlation of Mortality with Use of Central Venous Pressure Monitoring (C.V.P.M.) in 1966-8 in All Cases Pressure Monitoring (C.V.P.M.) in 1966-8 in All Cases
Where C.V.P.M. was Used, All Shocked Patients, All Patients Given Steroids, and All Patients Given Digitalis

\begin{tabular}{|c|c|c|c|c|c|c|c|}
\hline & & & & & \multirow{2}{*}{ Total } & \multicolumn{2}{|c|}{ Dead } \\
\hline & & & & & & No. & $\%$ \\
\hline \multirow{4}{*}{$\begin{array}{l}\text { All cases with C.V.P.M. } \\
\text { Shock: } \\
\text { All cases } \\
\text { Shock (with C.V.P. } . \dot{M} \text {.) } \\
\text { Shock (no C.V.P.M.) } \\
\text { Steroids: }\end{array}$} & . & .. & . & .. & 25 & 4 & 16 \\
\hline & .. & $\ldots$ & $\cdots$ & & 58 & 17 & 29 \\
\hline & . & . & . & .. & 22 & 3 & 14 \\
\hline & $\cdots$ & . & $\cdots$ & .. & 36 & 14 & 40 \\
\hline \multicolumn{8}{|l|}{ Steroids: } \\
\hline Steroids (with C.V.P.M.) & $\therefore$ & $\because$ & $\because$. & $\because$ & $\begin{array}{l}33 \\
22\end{array}$ & 11 & 33 \\
\hline Steroids (no C.V.P.M.) & $\because$ & $\because$ & $\because$ & $\cdots$ & 11 & 8 & 73 \\
\hline \multicolumn{8}{|l|}{ Digitalis: } \\
\hline All cases & .. & . & .. & .. & 27 & 9 & 33 \\
\hline Digitalis (with C.V.P.M.) & . & . & $\cdots$ & .. & 13 & 2 & 15 \\
\hline Digitalis (no C.V.P.M.) & & .. & $\cdots$ & .. & 14 & 7 & 50 \\
\hline
\end{tabular}

Corticosteroids.-In 1966-8 a total of 33 patients with shock received intravenous corticosteroids (Table VI). The mortality for these patients (33\%) was similar to that for all patients with shock in the same period (29\%). However, 22 patients who received steroids had fluid therapy monitored with a central venous pressure manometer and only three of these died $(14 \%)$. On the other hand, 11 patients who were given steroids did not have fluid therapy monitored in this way and eight of them died $(73 \%)$, the difference in mortality rate being highly significant $(\mathrm{P}<0.01)$. The dose of corticosteroids in the two groups was very similar, and the groups were also similar with respect to the underlying conditions of the patients and to the nature of the infecting organisms.

Digitalis.-Twenty-seven patients were treated with digitalis after developing septicaemia, either because they developed cardiac failure or because fluid therapy raised the central venous pressure without restoring the arterial blood pressure. The mortality rate in these patients was $33 \%$, but of the 13 patients who had their central venous pressure monitored only two died, whereas seven died out of the 14 patients who did not (Table VI). Neither steroids nor digitalis by themselves reduced the mortality rate, but when either was combined with rational replacement of fluid using a central venous pressure monitor the mortality fell to less than $15 \%$.

Vasopressor Drugs.--Seventeen patients who were shocked were treated with vasopressor agents in 1962-5 (10 with metaraminol and 7 with noradrenaline) and 10 of them died (mortality 59\%).

\section{Discussion}

The mortality rate of patients with septicaemia improved considerably in 1966-8, coinciding with a change in the therapeutic regimen. The mortality was halved in two groups of patients-all those with Gram-negative infections and all those with shock. The "shock" group included patients with Gramnegative and with Gram-positive septicaemia. Over the same period there was a threefold increase in the number of cases of septicaemia diagnosed compared with 1962-5. The increased survival in 1966-8 was not simply due to an increase in the detection of "mild" cases of "bacteraemia" that would have recovered anyway, since there were proportionately as many shocked cases in 1966-8 as in 1962-5. On the other hand, there was a greater awareness of septicaemia throughout the hospital, which might well have led to earlier and more frequent diagnosis and contributed to the improved survival and the apparent increase in incidence.

One therapeutic measure which is clearly associated with a reduced mortality is monitoring the central venous pressure to regulate the administration of fluids. This is shown in three groups of patients in 1966-8-those with shock, those treated with steroids, and those treated with digitalis (Table VI). In each case the mortality rate was reduced to $15 \%$ in patients who did have monitoring of central venous pressure. The importance of monitoring the central venous pressure is twofold. Firstly, when it is carried out properly it leads to closer observation by the medical staff and more intensive clinical care ; this may well have made a significant contribution to the improved mortality. Secondly, it provides a continuous index of the interaction of changes in blood volume, vascular capacity, and myocardial contractility, all of which are affected in patients with septicaemia and shock. In these patients the effective circulating blood volume is reduced and there is a progressive loss of vascular tone, expanding the capacity of the vascular bed, especially in veins (Thomas, $1956 ; Z$ weifach et al., 1956; Gilbert, 1960 ; Weil and Miller, 1961 ; Spink, 1962 ; Lillehei et al., 1964 ; Waisbren, 1964 ; Weil et al., 1964 ; Udhoji and Weil, 1965). These two factors caused a marked fall in central venous pressure but at the same time myocardial contractility is impaired, tending to raise the central venous pressure. By regulating the administration of fluid so as to keep the central venous pressure between arbitrary limits of 10 to $15 \mathrm{~cm}$. of water the function of both the heart and the peripheral circulation can be assisted to optimal performance under the prevailing conditions.

Myocardial impairment plays an important part in the shock of septicaemia, but is often overlooked, as it is not always clinically evident (Maclean et al., 1965; Siegel et al., 1967). Siegel et al. (1967) performed cardiac function curves in 30 patients with septicaemic shock and showed impaired contractility in all of them, even though many did not have clinical evidence of heart failure. Accordingly it seems reasonable to recommend giving digitalis to all patients with septicaemia and shock. When heart failure due to septic myocarditis is present the restoration of blood volume becomes very difficult, and in this situation monitoring of the central venous pressure is particularly valuable. This is shown in this series by the reduced mortality (15\%) in patients given digitalis who were monitored compared with those who were not $(50 \%)$.

The role of steroids in the treatment of shock in septicaemia is difficult to assess. There is good evidence that steroids are beneficial in experimental endotoxic shock in dogs, but this is not an ideal model for septicaemic shock in humans (Spink and Anderson, 1954 ; Thomas, 1956 ; Spink and Vick, 1961 ; Weil and Miller, 1961 ; Spink, 1962; Weil, 1962 ; Lillihei et al., 1964 ; Waisbren, 1964). The only evidence for benefit in humans comes from reports showing greater survival following the combination of steroids with vasopressor agents than after the use of vasopressor agents alone (Waisbren, 1964; Weil et al., 1964 ; Cavanagh and McLeod, 1966). In the present series there is no evidence that steroids improve survival. There is equally no evidence that they do not, since the shocked patients with the best survival rates-that is, those treated with central venous pressure monitoring-all received corticosteroids (Table VI). While it is clear that steroids alone, without central venous pressure monitoring, did not increase survival, it is possible that it was the combination of steroids with central venous pressure monitoring rather than central venous pressure monitoring alone which improved the survival in shocked patients. This question can only be resolved by a controlled prospective trial.

The data presented here failed to show any superiority for any one of the antibiotics used. However, when kanamycin was used it was given as initial therapy before sensitivity tests 
were available and had to cover a wide range of possible microorganisms, whereas other antibiotics were usually used only if sensitivity tests indicated they were appropriate. Therefore the fact that the mortality with kanamycin was the same as with other antibiotics suggests that the broad cover it affords in vitro is matched by efficacy in the Jatient, especially in Gramnegative infections. Once the results of blood cultures and sensitivity tests are at hand a charge of antibiotics is necessary in only a small percentage of infections, including those due to Ps. aeruginosa, which is probably best treated with carbenicillin (Jones and Lowbury, 1967 ; Knudsen et al., 1967 ; Stratford, 1968), and those due to Gram-positive cocci other than staphylococci. Of these, pneumococci and beta-haemolytic streptococci require high dosage of penicillin, which should be added to the initial antibiotic therapy whenever an infection due to one of these organisms is suspected. Str. faecalis will usually respond to ampicillin.

The failure to reduce the high mortality in staphylococcal septicaemia probably stems from two factors. Firstly, the diagnosis is often delayed, perhaps because shock is not very common and occurs late. Secondly, there was usually no specific antibiotic therapy against the staphylococcus in the current series until the culture results were known. While kanamycin did provide in-vitro cover against Staph. aureus in $92 \%$ of the present cases, it may not be as effective in viro, and since May 1968 methicillin has been combined with kanamycin for the initial antibiotic therapy of suspected septicaemia pending the results of blood cultures. Recent reports of increasing incidence of methicillin-resistant staphylococci (Benner and Kayser, 1968 ; Rountree and Beard, 1969) suggest that staphylococcal septicemia will continue to present a therapeutic problem.

We are indebted to Dr. P. M. Rountree for her advice and encouragement.

\section{REFERENCES}

Anderson, R. W., James, P. M., Bredenberg, C. E., and Hardaway, R. M. (1967). Annals of Surgery, 165, 341.

Benner, E. J., and Kayser, F. H. (1968). Lancet, 2, 741.
Bennett, I. L., Finland, M., Hamburger, M., Kass, E. H., Lcpper, M. and Waisbren, B. A.' (1963). Journal of the American Medical Association, 183, 462 .

Blair, E., Buxton, R. W., Cowley, R. A., and Mansberger, A. R., jun. (1961). Fournal of the American Medical Association, 178, 916.

Cavanagh, D., and McLeod, A. G. W. (1966). American Fournal of Obstetrics and Gynaecology, 96, 913.

du Toit, H. J., du Plessis, J. M. E., Dommisse, J., Rorke, M. J., Theron, M. S., and de Villiers, V. P. (1966). Lancet, 2, 143.

Gilbert, R. P. (1960). Physiological Reviews, 40, 245.

Gourzis, J. T., Hollenberg, M. W., and Nickerson, M. (1961). Fournal of Experimental Medicine, 114, 593.

Hassall, J. E., and Rountree, P. M. (1959). Lancet, 1, 213.

Hodgin, U. G., and Sanford, J. P. (1965). American fournal of Medicine, 39, 952.

Jones, R. J., and Lowbury, E. J. L. (1967). British Medical fournal, 3,

79.
Kardos, G. G. (1966). New England fournal of Medicine, 274, 868

Knudsen, E. T., Rolinson, G. N., and Sutherland, R. (1967). British Medical fournal, 3, 75.

Lillihei, R. C., Longerbeam, J. K., Bloch, J. H, and Manax, W. G. (1964). Clinical Pharmacology and Therapeutics, 5, 63.

McCabe, W. R., and Jackson, G. G. (1962). Archives of Internal Medicine, $110,856$.

McGowan, G. K., and Walters, G. (1963). British fournal of Surgery, 50, 821 .

McHenry, M. C., Martin, W. J., and Wellman, W. E. (1962). Annals of Internal Medicine, 56, 207.

Maclean, L. D., Duff, J. H., Scott, H. M., and Perctz, D. I. (1965). Surgery, Gynaecology and Obstetrics, 120, 1.

Melby, J. C., and Spink, W. W. (1958). Fournal of Clinical Investigation, 37, 1791 .

Prout, W. G. (1968). Lancet, 1, 1108.

Rountree, P. M., and Beard, M. A. (1969). Medical fournal of Australia. In press.

Siegel, J. H., Greenspan, M., and Del Guercio, L. R. M. (1967), Annals of Surgery, 165, 504 .

Smith, L. L., and Moore, F. D. (1962). New England Fournal of Medicine, 267, 733

Spink, W. W. (1962). Annals of Internal Medicine, 57, 538 .

Spink, W. W. and Anderson, D. (1954). Fournal of Clinical Investigation, 33, 540 .

Spink, W. W., and Vick, J. (1961). Circulation Research, 9, 184.

Stratford, B. C. (1968). Medical Fournal of Australia, 2, 890 .

Thomas, L. (1956). Fournal of Experimental Medicine, 104, 865.

Udhoji, V. N., and Weil, M. H. (1965). Annals of Internal Medicine, 62, 966.

Waisbren, B. A. (1964). American fournal of Medicine, 36, 819.

Weil, M. H. (1962). Circulation, 5, 718.

Weil, M. H., and Miller, B. S. (1961). Fournal of Laboratory and Clinical Medicine, 57, 683.

Weil, M. H., Shubin, H., and Biddle, M. (1964). Annals of Internal Medicine, 60, 384.

Zweifach, B. W., Nagler, A. L., and Thomas, L. (1956). Fournal of Experimental Medicine, 104, 881.

\title{
Diurnal Variation of Oral Glucose Tolerance : a Possible Pointer to the Evolution of Diabetes Mellitus
}

\author{
R. J. JARRETT,* M.D. ; H. KEEN, $\dagger$ M.B., B.S., M.R.C.P.
}

\begin{abstract}
Cummary : Possible diurnal variation in the blood sugar $\checkmark$ response to oral glucose was studied by comparing, in the same individuals, the results of oral glucose tolerance tests performed in the morning and the afternoon. In a group of normal individuals the blood sugar levels were significantly higher in the afternoon. In hyperglycaemic individuals the diurnal variation decreased as the blood sugar levels reached during the morning test increased, so that in a group of grossly hyperglycaemic men the mean morning and afternoon tests were almost identical. The causes of this diurnal variation are not known.
\end{abstract}

* Lecturer, Department of Medicine, Guy's Hospital, London S.E.1. † Reader in Medicine, Guy's Hospital, London S.E.1.

\section{Introduction}

The traditional oral glucose tolerance test performed after an overnight fast is not very reproducible (McDonald et al., 1965). Some of the factors responsible for variation within individuals are known to include the level of the previous carbohydrate intake, the rate of gastric emptying, perhaps the emotional state, and, in women, the stage of the menstrual cycle. One other factor which might affect glucose tolerance-namely, the time of day at which the test is made-has received little attention. Its immediate practical importance lies particularly in the field of population surveys, for it is obviously more convenient to perform screening tests throughout the working day than to restrict them to the early morning.

In the Tecumseh population survey (Hayner et al., 1965) 